\section{Restrictive cardiomyopathy with ring chromosome 6 anomaly in a child}

\author{
Süleyman Sunkak* (D), Aslıhan Kiraz** (D), Mustafa Argun* (D), \\ İlkay Erdoğan1 (iD
}

Departments of *Pediatric Cardiology, and **Medical Genetics, Kayseri City Hospital; Kayseri-Turkey

1Department of Pediatric Cardiology, Faculty of Medicine, Başkent

University; Ankara-Turkey

\section{Introduction}

Restrictive cardiomyopathy (RCM) is a rare disease characterized by restrictive filling and decreased diastolic volume of the heart. It is the rarest cardiomyopathy among all cardiomyopathies with approximately $2.5 \%-5 \%$ ratio (1). The prognosis is poor and if transplant is not performed, death usually occurs two to three years after diagnosis (2).

The ring chromosome 6 anomaly is an extremely rare chromosomal anomaly. It is formed by breakage in the terminal portions of chromosome 6 and then the re-fusion of these broken terminal parts (3). This article reports a case of RCM with a ring chromosome 6 anomaly [r6 (p25q27)], which to the authors' knowledge, has not previously been reported in the literature.

\section{Case Report}

A 10-year-old girl was admitted to the hospital with a cough. The physician detected a grade 3 to 4 systolic murmur. Her oxygen saturation was $98 \%$. She had microcephaly, hypertelorism, micrognathia, broad nasal bridge, a high-arched palate, clinodactyly in the right hand, and pes planus.

The transthoracic echocardiographic examination showed bi-atrial enlargement in the apical four-chamber view (Video 1). There was a $4 \mathrm{~mm}$ secundum atrial septal defect (ASD), and the flow direction was from right to left. Left ventricle ejection fraction and fractional shortening were normal. The mitral insufficiency jet flow $(3.9 \mathrm{~m} / \mathrm{sec}, 4.8 \mathrm{~cm})$ was large-eccentric and adhered to the posterior wall of the left atrium. The mitral E/A ratio was 3.75 (E: $1.71 \mathrm{~m} / \mathrm{sec}, \mathrm{A}: 0.46 \mathrm{~m} / \mathrm{sec}$ ). The tricuspid valve insufficiency jet flow was $3.9 \mathrm{~m} / \mathrm{sec}$.

Pressure measurements were performed invasively. The main pulmonary artery pressure was $101 / 51$ (73) $\mathrm{mm} \mathrm{Hg}$, aorta $91 / 59(71) \mathrm{mm} \mathrm{Hg}$, right atrium $24 \mathrm{~mm} \mathrm{Hg}$, and left atrium 26 $\mathrm{mm} \mathrm{Hg}$. The pulmonary vascular resistance index (PVRI) was 7.6 WUm², systemic vascular resistance index (SVRI) was 12.7 WUm², PVRI/SVR was 0.59 .

Chromosome analysis was conducted on 72-hour culture, and GTG banding was used to examine peripheral leukocytes. The result was interpreted according to the International Hu-

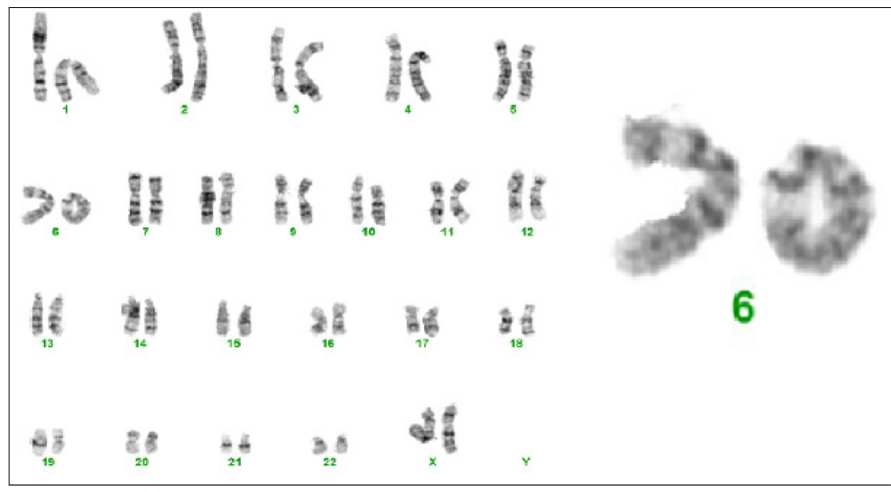

Figure 1. Karyotype analysis images of the patient with $46, X X, r(6)(p 25 q 27)$ variation

man Cytogenetic Naming System (ISCN 2016) (4). The karyotype was $46, X X, r(6)(p 25 q 27)$. Chromosome 6 had a ring formation in all of the prepared and examined slides (Fig. 1). Molecular karyotyping was performed with HumanCytoSNP-12 BeadChip $300 \mathrm{~K}$ array. Data were analyzed using BlueFuse Multi 4.5 and revealed arr [GRCh38] 6p25.3p25.2(204409_3716890)x1. The parents were in a consanguineous marriage, and their karyotype analysis were normal. Their results demonstrated a de novo origin of $r(6)$.

\section{Discussion}

RCM is a myocardial disease characterized by increased myocardial stiffness and decreased ventricular filling (5).

Many sarcomeric and non-sarcomeric mutations have been identified in the etiology of RCM. However, in addition to structural protein mutations, we detected a ring chromosome 6 anomaly in this patient.

Ring chromosome 6 is a rare chromosome abnormality that occurs de novo, usually via the breakage of the terminal parts of chromosome 6 and the subsequent fusion of these breaking points. The clinical findings on chromosome 6 ring are highly variable; however, more common and consistent clinical findings include growth retardation, mental retardation, and hypertelorism as was the case with our patient (6). Ever since Moore et al. first described ring chromosome 6 disease in 1973, multiple case reports have emerged in the literature $(3,7)$. We could not find any cases featuring dilated or RCM among these reports. Pace et al. (8) reported a 49-year-old patient with dysmorphic findings and mild right and left ventricular hypertrophy and small ASD. Here, the ring formed in $6 \mathrm{p} 25.3 \mathrm{q} 27$ and featured both a distal $6 p$ deletion and a distal $6 q$ duplication. Ciocca et al. (9) reported a newborn girl with a large patent ductus arteriosus (PDA) and secundum ASD. In that patient, the breakpoints were at p25 and q27, similar to our case. Lee et al. (10) have reported a 7-day-old newborn with a large PDA and a mosaic pattern ring chromosome 6. However, we did not find any patients with ring chromosome 6 cardiomyopathy (neither dilated nor restrictive) in the literature. 


\section{Conclusion}

RCM is an uncommon disease with high mortality, and its genetic basis has not been fully understood. Ring chromosome 6 , whose clinical findings vary from case to case, is an extremely rare chromosomal anamoly. We believe that this case, which was reported for the first time, will contribute to the literature.

Informed consent: Written informed consent form was obtained from the parent.

Video 1. Biatrial enlargement with normal ventricle sizes in apical four-chamber view

\section{References}

1. Malcić I, Jelusić M, Kniewald H, Barisić N, Jelasić D, Bozikov J. Epidemiology of cardiomyopathies in children and adolescents: a retrospective study over the last 10 years. Cardiol Young 2002; 12: 253-9.

2. Walsh MA, Grenier MA, Jefferies JL, Towbin JA, Lorts A, Czosek RJ. Conduction abnormalities in pediatric patients with restrictive cardiomyopathy. Circ Heart Fail 2012; 5: 267-73.

3. Moore CM, Heller RH, Thomas GH. Developmental abnormalities associated with a ring chromosome 6. J Med Genet 1973; 10: 299303.

4. McGowan J, Simons A, Schimd M, Switzland S, Karger A. ISCN 2016: An International System for Human Cytogenetic Nomenclature. [Place unknown]: Karger; 2016.
5. Denfield SW, Webber SA. Restrictive cardiomyopathy in childhood. Heart Fail Clin 2010; 6: 445-52.

6. Sheth F, Liehr T, Shah V, Shah H, Tewari S, Solanki D, et al. A child with intellectual disability and dysmorphism due to complex ring chromosome 6: identification of molecular mechanism with review of literature. Ital J Pediatr 2018; 44: 114.

7. Zhang R, Chen X, Li P, Lu X, Liu Y, Li Y, et al. Molecular characterization of a novel ring 6 chromosome using next generation sequencing. Mol Cytogenet 2016; 9: 33.

8. Pace NP, Maggouta F, Twigden M, Borg I. Molecular cytogenetic characterisation of a novel de novo ring chromosome 6 involving a terminal $6 p$ deletion and terminal $6 q$ duplication in the different arms of the same chromosome. Mol Cytogenet 2017; 10: 9.

9. Ciocca L, Surace C, Digilio MC, Roberti MC, Sirleto P, Lombardo A, et al. Array-CGH characterization and genotype-phenotype analysis in a patient with a ring chromosome 6. BMC Med Genomics 2013; 6: 3

10. Lee SJ, Han DK, Cho HJ, Cho YK, Ma JS. Mosaic ring chromosome 6 in an infant with significant patent ductus arteriosus and multiple congenital anomalies. J Korean Med Sci 2012; 27: 948-52.

Address for Correspondence: Dr. Süleyman Sunkak, Kayseri Şehir Hastanesi, Pediatrik Kardiyoloji Kliniği, Kayseri-Türkiye

E-mail: suleymansunkak@gmail.com

Phone: (0352) 3157700

(C) Copyright 2021 by Turkish Society of Cardiology -

Available online at www.anatoljcardiol.com

DOI:10.5152/AnatolJCardiol.2021.80820 